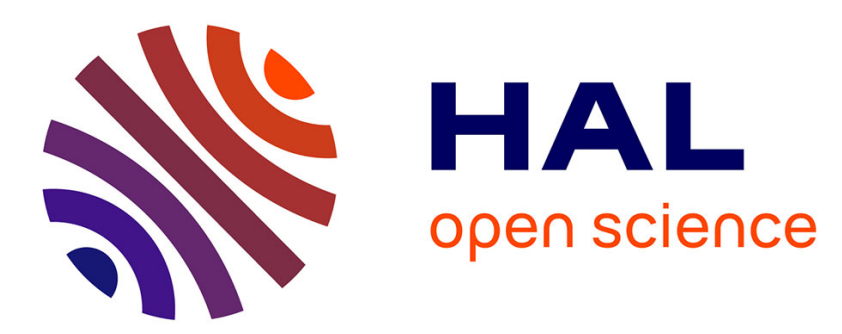

\title{
Mechanical potential of eco-OSB produced from durable and nondurable species and natural resins
}

Olivier Arnould, Reinhard Stürzenbecher, Sandrine Bardet, Karin Hofstetter, Daniel Guibal, Nadine Amusant, Antonio Pizzi

\section{- To cite this version:}

Olivier Arnould, Reinhard Stürzenbecher, Sandrine Bardet, Karin Hofstetter, Daniel Guibal, et al.. Mechanical potential of eco-OSB produced from durable and nondurable species and natural resins. Holzforschung, 2010, 64 (6), pp.791-798. 10.1515/HF.2010.116 . hal-00689006

\section{HAL Id: hal-00689006 https://hal.science/hal-00689006}

Submitted on 19 Apr 2012

HAL is a multi-disciplinary open access archive for the deposit and dissemination of scientific research documents, whether they are published or not. The documents may come from teaching and research institutions in France or abroad, or from public or private research centers.
L'archive ouverte pluridisciplinaire HAL, est destinée au dépôt et à la diffusion de documents scientifiques de niveau recherche, publiés ou non, émanant des établissements d'enseignement et de recherche français ou étrangers, des laboratoires publics ou privés. 
2 Mechanical potential of eco-OSB produced from durable and nondurable species and natural resins

4 Olivier Arnould*1, Reinhard Stürzenbecher ${ }^{2}$, Sandrine Bardet ${ }^{1}$, Karin Hofstetter ${ }^{2}$,

$5 \quad$ Daniel Guibal ${ }^{3}$, Nadine Amusant ${ }^{3}$ and Antonio Pizzi ${ }^{4}$

${ }^{1}$ Laboratoire de Mécanique et Génie Civil, Université Montpellier 2, CNRS UMR5508, CC 048 Place Eugène Bataillon, 34095 Montpellier, France

${ }^{2}$ Institute for Mechanics of Materials and Structures, Vienna University of Technology, Karlsplatz 10 13/202, 1040 Vienna, Austria

$11{ }^{3}$ CIRAD-UR 40, 73 rue J.F. Breton, TA 10/16 34398, Montpellier Cedex 5, France

${ }^{4}$ Laboratoire d'Etudes et de Recherche sur le Matériau Bois, Ecole Nationale Supérieure des Technologies et Industries du Bois, Université Henri Poincaré, 27 rue du merle blanc, BP 1041, 88051 Epinal Cedex 9, France

*Corresponding Author: E-mail: olivier.arnould@univ-montp2.fr, Tel: +33 (0)4 671496 50, Fax: +33(0)467144792

\section{Abstract}

OSB panels were manufactured with different mixtures of pine and cypress heartwood and resins based on lignin or tannin in order to develop an eco-friendly wood composite with a natural durability against termite and fungi. Some physical properties and the major elastic moduli of bulk wood as well as of the manufactured panels were determined using different measurement techniques. In addition, a micromechanical model was adapted and validated with the experimental results. The good agreement obtained between the experimental data and model predictions indicates the proper assessment of the most influential parameters, such as raw material and adhesive properties, strand orientation, layer assembly, and density profile. A parameter study, enlightening the effect of strand orientation on several elastic constants, enlarges the scope of experiments. We conclude with an optimal combination of resin and wood species mixture resulting in the best performance from a biological and mechanical standpoint.

Keywords: mechanical properties, micromechanical modelling, natural resin, OSB, pine and 
Most of the wood-based composites are not naturally resistant to termite attack (Muin and Tsunoda 2003) because they are mainly manufactured from non durable wood species. Panels designed for end uses, in which decay or termite attack are potential hazards, often contain fungicides or insecticides. Leachability and toxicity are major problems for this type of products. Nowadays, the pressure to restrict the use of wood preservatives in wood products is increasing. Moreover, interactions between adhesives and preservatives damage the bond performance and ultimately reduce the physical properties of the panel (Goroyias and Hale 2004, Kirkpatrick and Barnes 2006). Thus, alternative approaches are necessary to obtain good durability of environmentally friendly wood composites without loss of performance.

Modern product developments should consider both ecological and technical aspects. The resistance of wood products to biodegradation can be increased by using naturally durable wood species, especially in regions with low to moderate termite hazard (Behr 1972, Yalinkilic et al. 1998, Evans et al. 2000, Kartal and Green 2003, Wan et al. 2007). Another environmental concern is the control of volatile and semi-volatile compounds derived mainly from adhesives (resins). Natural resins based on lignin (Lei et al. 2007, Mansouri et al. 2007a) or tannin (Garnier et al. 2002, Ballerini et al. 2005) are options for environment-friendly products.

A political concern nowadays is on reducing the emission of climate gases (mainly $\left.\mathrm{CO}_{2}\right)$ in production processes. Wood and wood products are a priori ecological materials, especially if productions processes are well optimized with reduced energy consumption (ECOSB 2008) and residues (by-products). Oriented strand board (OSB) panels are exemplary with this regard as their production permits the utilization of almost all the harvested trees including imperfect or young trees and fast growing species.

Results on the durability of ecological OSB products (shortly 'eco-OSB') have been published recently (Amusant et al. 2009). It has been shown that OSB made of a mixture of heartwood cypress (Cupressus sempervirens) and pine (Pinus sylvestris), with lignin (with 
61 paraformaldehyde and pMDI) or tannin (from pine with hexamine hardener)-based resin, show 62 durability against termites and fungi.

The load bearing capacity of OSB panels in structural applications is essential. Thus, this paper focuses on the mechanical potential of these eco-OSBs. Firstly, mechanical properties of the raw material and of eco-OSB will be identified by several mechanical testing methods. Secondly, a micromechanical model will be applied, which provides a link between microstructural characteristics and the macroscopic mechanical behaviour. In particular, the overall elastic properties of the panels will be estimated considering the physical properties of bulk wood and resin as well as the morphological characteristics of the OSB such as strand orientation, density profile and layer assembly. The motivation for the modelling is to further explore the mechanical potential of the panels beyond the traditional experiences. The micromechanical model should serve as the basis for product development and optimisation. The expectation is that it allows identifying optimal panel designs in terms of microstructural characteristics and panel lay-ups.

\section{Materials and methods}

\section{Characterization of the raw materials}

OSB was produced of cypress heartwood, which is naturally durable against termites, and sap- and heart-wood of pine, which are both nondurable against termites. The different 60 -year old trees were grown in the Grenouillet Arboretum (France), felled, and crosscut into $1 \mathrm{~m}$ long logs. Test specimens for determination of physical and mechanical properties were cut from the logs as

81 depicted in Figure 1. All specimens, i.e., the raw material and the OSB panels, were conditioned and tested at a temperature of $20^{\circ} \mathrm{C}$ and a relative humidity $(\mathrm{RH})$ of $65 \%$. First, static compression tests on cubes, with a side length of $40 \mathrm{~mm}$ machined along the principal material directions $(\mathrm{R}, \mathrm{T}$ and L) were performed on a universal electromechanical testing machine MTS 1/ME with a $5 \mathrm{kN}$ load cell. Mean compression strain was assessed by using strain gages (from Kyowa and TML with 
calculating the elastic moduli $E_{\mathrm{R}}, E_{\mathrm{T}}$ and $E_{\mathrm{L}}$. Moreover, transversally oriented gages were used to measure the transverse strains on each of the four accessible faces of the cubes for determination of the six Poisson's ratios $v_{\mathrm{RT}}, v_{\mathrm{T}}, v_{\mathrm{LT}}, v_{\mathrm{TL}}, v_{\mathrm{LR}}$ and $v_{\mathrm{RL}}$. The maximum applied load corresponds to a mean compressive strain of around $0.2 \%$. The test consists in three loading/unloading cycles at a strain rate of about $10^{-4} \mathrm{~s}^{-1}$. The elastic moduli are measured in the linear range of the unloading/reloading curves.

In addition, Bordonné's free vibration beam method (Bordonné 1989, Brancheriau and Bailleres 2002) was applied on samples sized $20 \times 20 \times 360 \mathrm{~mm}^{3}$ (R-T-L). It allows measuring longitudinal bending elastic modulus, $E_{\mathrm{L}}$, and shear moduli, $G_{\mathrm{TL}}$ or $G_{\mathrm{LR}}$ depending on the sample rotation along the L-direction, at the natural frequency of the beam, which is approximately $700 \mathrm{~Hz}$. Furthermore, ultrasound measurements in the directions of the principal axes have been performed by means of Sofranel's $1 \mathrm{MHz}$ longitudinal transducer on cubes with side lengths of $20 \mathrm{~mm}$ cut at the end of the free vibration beam (see Figure 1). Determining the ultrasound velocity $V$ in the sample (Bucur 2005) and knowing the density $\rho$, it is possible to compute the elastic stiffness $C_{\mathrm{ii}}$ of the sample that is linked to the modulus of elasticity $E_{\mathrm{i}}$ and the Poisson's ratios $v_{\mathrm{ij}}$ (Guitard 1989):

$$
E_{\mathrm{i}}=\frac{1-v_{\mathrm{TR}} v_{\mathrm{RL}} v_{\mathrm{LT}}-v_{\mathrm{LR}} v_{\mathrm{RT}} v_{\mathrm{TL}}-\left(v_{\mathrm{TL}} v_{\mathrm{LT}}+v_{\mathrm{TR}} v_{\mathrm{RT}}+v_{\mathrm{LR}} v_{\mathrm{RL}}\right)}{1-v_{\mathrm{jk}} v_{\mathrm{kj}}} C_{\mathrm{ii}}
$$

where $C_{\mathrm{ii}}=\rho V_{\mathrm{i}}^{2}$ and $\mathrm{i}, \mathrm{j}, \mathrm{k}=\{\mathrm{R}, \mathrm{T}, \mathrm{L}\}$, e.g., if $\mathrm{i}=\mathrm{R}$ then $1-\boldsymbol{v}_{\mathrm{jk}} \boldsymbol{v}_{\mathrm{kj}}=1-\boldsymbol{v}_{\mathrm{TL}} \boldsymbol{v}_{\mathrm{LT}}$. Assuming a negligible effect of loading frequency on the Poisson's ratios, their values obtained with the compression tests are used to compute the elastic modulus $E_{\mathrm{i}}$ from $C_{\mathrm{ii}}$.

A micromechanical model by Hofstetter et al. $(2005,2006,2007)$ was also applied because a complete and consistent set of all nine independent elastic constants of the bulk wood was not always available or reliable. This model allows the prediction of the elasticity tensor of various wood species from the elastic properties of the basic constituents of wood (cellulose, hemicelluloses, lignin and water) and from morphological parameters such as microfibril angle (MFA), cell arrangement and macroscopic density. In order to estimate the properties of the raw 
112 material, density was chosen in accordance with the mean density of the tested bulk wood samples.

113 The microstructural characteristics, MFA and the lignin content, were determined by adjusting the

114 resulting model predictions of $E_{\mathrm{L}}, E_{\mathrm{T}}$ and $G_{\mathrm{TL}}$ to the corresponding experimental results from

115 bending free vibration and compression tests. The model estimated stiffness tensor obtained for

116 these microstructural characteristics was finally used as input for the panel model presented below.

117 Manufacturing OSB panels

118 Flakes with dimensions of $0.6 \times 10 \times 100 \mathrm{~mm}^{3}(\mathrm{R}-\mathrm{T}-\mathrm{L})$ were manually trimmed in thin veneers and

119 the flakes of each species were dried to about 6-7\% moisture content (MC) before gluing. Mat

120 formation and strand orientation were done by hand. The full set of panel manufacturing parameters

121 is presented in Table 1. A total of 24 OSB panels was prepared, which corresponds to three panels

122 for each combination of resin and species.

123 Characterization of OSB test specimens

124 From each panel, 18 squared test specimens with dimensions of $50 \times 50 \times 14 \mathrm{~mm}^{3}$ and 2 beams (one 125 sized $300 \times 40 \times 14 \mathrm{~mm}^{3}$, mainly oriented in the $x$-direction, and one sized $260 \times 40 \times 14 \mathrm{~mm}^{3}$, mainly 126 oriented in the $y$-direction) were cut (Figure 2). The beams and part of the squared specimens were 127 used for determination of the elastic properties of the panels, while the remaining squared 128 specimens were employed for the durability measurements (Amusant et al. 2009).

129 The mean density was measured for each test specimen. The vertical density profile was 130 determined by means of the densitometer DENSE-LABX (Electronic Wood System, Germany) at 131 increments of $0.05 \mathrm{~mm}$ for ten randomly chosen specimens. The strand orientation distribution was 132 determined manually using pictures of the outer surfaces of three different panels (Figure 2) and 133 ImageJ, a public domain image processing software.

134 Classical static face down 4 point-bending test (outer span: $250 \mathrm{~mm}$, inner span: $160 \mathrm{~mm}$, 135 loading point diameter: $20 \mathrm{~mm}$ ) were first done on the beam-shaped sample using again the 136 electromechanical testing machine MTS 1/ME equipped with a $5 \mathrm{kN}$ load cell, at a loading speed of $13710 \mu \mathrm{m} \mathrm{s}^{-1}$ in order to reach the ultimate loading force in $300 \pm 120 \mathrm{~s}$ following EN 789 European 
138

139

140

standard (2005). The tests were performed in the elastic range, and the bending strain was measured through the difference in deflection between three points by means of a micrometer mounted on a specific fitting. Accordingly, the static bending moduli of elasticity in the two main panel directions, $E_{x}$ and $E_{y}$, were obtained. In addition, the same samples were tested in free vibration bending using Bordonné's principle (Bordonné 1989, Brancheriau and Bailleres 2002). Face down measurements allow to determine the bending moduli of elasticity, $E_{x}$ and $E_{y}$, at a frequency of around $500 \mathrm{~Hz}$ and edgewise measurements yield estimates of the shear elastic modulus $G_{\mathrm{xy}}$ (Brancheriau 2006) on the two types of beams ( $x$ and $y$-direction). Finally, ultrasound measurements through the thickness of the squared specimens were performed in order to obtain the elastic stiffness $C_{z z}$.

\section{Modelling the elastic properties of the panels}

A multiscale model for strand-based engineered wood products developed by Stürzenbecher et al. (2010a, b) was applied and adapted to the specific characteristics of the present panels. This multiscale model is based on the continuum micromechanics and lamination theory and predicts the in-plane tension and bending stiffnesses as well as the in-plane shear stiffness of multi-layer strand boards. Thereby, the boards are idealized consisting of ellipsoidally shaped and perfectly bonded wood strands. The following parameters are considered: the elastic properties of the wood species, the slenderness ratio and orientation distribution of the strands, as well as the panel lay-up described in terms of density profile and layer assembly. Here only the specifications of the model for the present study are explained. For a detailed description of the model approach, see Stürzenbecher et al. (2010b). The high resin mass content of the produced boards (Table 1), which equals about $6 \%$ (by volume) of the final boards, requires an adjustment of the original model. This model had been developed for strand boards with moderately low resin content, which did not necessitate consideration of the adhesive as a separate material phase. In order to account properly for the higher adhesive content in this application, strands were modelled with an adhesive layer, applying the Composite Cylinder Assemblage (CCA) model for estimating their elastic properties (Hashin 
and Rosen 1964, Hashin 1979). The transverse shear modulus, which cannot be estimated by means of the CCA model, was predicted by a Generalised Self Consistent Scheme developed by Christensen and Lo (1979). Based on the estimated elastic properties of adhesive coated strands, the homogenization procedure of Stürzenbecher et al. (2010b) was applied, accounting for the compaction, the strand orientation distribution, the layer assembly and the density profile across the panel thickness. The elastic behaviour of the tannin and the lignin adhesives in their cured state was assumed to be isotropic with a Poisson's ratio of 0.3 and a modulus of $1.8 \mathrm{GPa}$ (Garcia and Pizzi 1998, Osman and Pizzi 2002) and 2.1 GPa (Mansouri et al. 2007b), respectively. Since the density profiles were not measured at every test specimen, one characteristic representative of all measured density profile was taken for modelling of all panels. This procedure was feasible, since the production process was the same for all panel types and only little variation was observed between the measured density profiles.

Extending the original model by Stürzenbecher et al. (2010b), the stiffness component $C_{z z}$ in the plate thickness direction was estimated from the respective values of the individual board layers with different densities. This was done using the rule of mixtures for serially arranged materials, reading mathematically as:

$$
C_{z z}=\frac{1}{\sum_{i=1}^{N} \frac{f_{i}}{C_{z z_{i}}}}
$$

181 where $f_{i}$ denotes the relative layer thickness and $C_{z z_{i}}$ the stiffness tensor component of this layer $i$ in the thickness direction of the panel.

\section{Results and discussion}

Density and mechanical properties of the raw materials

The data for density and elastic properties of the bulk wood are reported in Table 2. For the static compression tests, only one sample per species was tested several times. This may explain the very low standard deviation of the respective results. For the compression tests on pine, Poisson's ratio 
$v_{\mathrm{LR}}$ is missing because of experimental difficulties. The measurement of Poisson's ratio $v_{\mathrm{LT}}$ is difficult as well, leading to too high values on one side of the sample, of only limited reliability, that

191 leads to the high standard deviation reported. The values for $v_{\mathrm{LT}}$ have been checked by measuring $v_{\mathrm{TL}}$ as well, but the measurement results were not better in this case due to the small absolute values of these ratios. The results for the longitudinal elastic moduli, $E_{\mathrm{L}}$, of the raw material measured by different techniques are in reasonably good agreement with each other. Similarly good agreement is obtained for the elastic moduli $E_{\mathrm{T}}$ and $E_{\mathrm{R}}$ determined by ultrasound measurements and static compression tests. The beam free vibration measurements delivered in addition to the $E_{\mathrm{L}}$ both shear moduli $G_{\mathrm{TL}}$ and $G_{\mathrm{LR}}$. Values obtained with this last method for $E_{\mathrm{L}}$ are in good agreement with the other ones even if it corresponds in that case to bending loading. This may be due to the relatively good homogeneity of the material at the considered cross section scale.

Microstructural characteristics of bulk wood were back-calculated by the micromechanical model (Hofstetter et al. 2005, 2006, 2007) based on the values of $E_{\mathrm{L}}, E_{\mathrm{T}}$ and $G_{\mathrm{TL}}$ measured with the bending free vibration technique. MFAs of $21^{\circ}$ were obtained for pine and $22^{\circ}$ for cypress, whereby the lignin content of the former was $20 \%$ and $26 \%$ of the latter, which is in the range of possible mean lignin contents for softwood from 25 to $34 \%$ after Petterson (1984) or from $20 \%$ to $27 \%$ after Faix (2008). Accordingly, the micromechanical model provides a full set of elastic constants of the 206 (orthotropic) raw material, which is in full agreement with those obtained from experiments 207 (Table 2).

208 Structural characterization of the produced strand boards

209 The average density of all panels is about $656 \mathrm{~kg} \mathrm{~m}^{-3}$ with a standard deviation of $24 \mathrm{~kg} \mathrm{~m}^{-3}$. Figure 2103 shows the characteristic measured density profile, which was used for the evaluation of the model 211 for eco-OSB panels. It exhibits a moderate U-shape, as all the measured density profiles. For 212 modelling purpose, this profile was discretized: constant density values were determined for layer 213 thicknesses between $0.5 \mathrm{~mm}$ close to the surfaces and $2.5 \mathrm{~mm}$ in the centre of the board (Figure 3). 
214 The strand orientation distribution measured on the surfaces of three different panels is depicted in

215 Figure 4. A classical spread of orientations is observed, and a normal distribution was adjusted by

216 the least-square method. This yields a mean orientation close to $0^{\circ}$ and a standard deviation around

$2175^{\circ}$, reflecting the careful panel production by hand, which achieves better alignment of strands than

218 industrial processes.

219 Mechanical properties of the produced strand boards

220 The elastic properties of the final OSBs, measured with different techniques, are presented in Table

2213 and grouped according to the mixture of wood species and the resin types. Here, the medians and

222 the ranges are given, showing the difference between the maxima and the minima of the three 223 replicates of each setting.

The values obtained in static bending are in good agreement with those obtained in free vibration despite the difference in the loading frequency. Free vibration yielded quite similar results 226 for the in-plane shear-modulus obtained for the beams oriented in $x$ and $y$-direction. The order of 227 the values of the measured moduli is as expected, i.e., $E_{x}>E_{y}>G_{x y}$, because $E_{x}$ and $E_{y}$ are mainly 228 linked to $E_{\mathrm{L}}$ and $E_{\mathrm{T}}$ of the bulk wood, respectively, as the outer layers contribute dominantly to the overall bending stiffness of the panels. Remarkably, the results for the elastic moduli do not 230 correlate with the amount of cypress in the mixture except for the stiffness $C_{z z}$. The latter decreases 231 when the amount of cypress is reduced irrespective of the resin. This is in line with the slightly 232 higher moduli $E_{\mathrm{R}}$ measured on the bulk wood samples of cypress than on those of pine. For the 233 bending moduli $E_{\mathrm{x}}$ and $E_{\mathrm{y}}$ measured on the panel, the effect of cypress content is not obvious, 234 probably because the two moduli of the bulk material controlling the panel bending stiffness, 235 namely $E_{\mathrm{T}}$ and $E_{\mathrm{L}}$, are close to each other for the two species, as can be seen in Table 2 . The 236 variability of the out-of-plane modulus rather results from variations of the wood and resin 237 properties in individual panels than from different extents of bonding defects. On the other hand, 238 the variability of the bending properties of the panels is - amongst others - a consequence of 239 varying bonding quality between strands. Altogether, the mechanical properties were comparable to 
that of conventional, industrially produced boards, highlighting the potential of the investigated bio-

241 composite. In this study, panels made with lignin-based resin give the best results in terms of elastic 242 properties. This is all the more interesting as lignin-based resin yields the best durability too 243 (Amusant et al. 2009).

244 Comparison of model predictions and experimental results

245 The suitability of the micromechanical model was validated experimentally. For this purpose, the 246 model is evaluated with the specifications of the produced boards, including the elastic properties of 247 the raw material and resin, the characteristic density profile adjusted to the mean final density, the 248 strand orientation distribution and the layer assembly. Thereupon, a one-to-one comparison is made 249 between the model estimates and the corresponding results of bending free vibration tests $\left(E_{x}, E_{y}\right.$ 250 and $G_{x y}$ ) and ultrasonic experiments $\left(C_{z z}\right)$, respectively (Figure 5). Both MOE, $E_{x}$, and $E_{y}$, estimated 251 by the model show on average good agreement with the experimental results obtained from bending 252 free vibration tests. Natural fluctuations of elastic properties of the raw material and variations in 253 the production process were not considered in the model, so that the considerable variations of the experimental results were not reproduced by the model. The mean prediction error of the MOE $E_{x}$ amounts to $12.1 \%$ with a standard deviation of $17.1 \%$, while it is $3.8 \%$ with a standard deviation of $21.4 \%$ for $E_{\mathrm{y}}$. The in-plane shear modulus $G_{x y}$ is overestimated by the model by $24.6 \%$ with a 257 standard deviation of prediction errors of 46.5\%. Particularly, experimental shear moduli below $2581 \mathrm{GPa}$ are not well predicted by the model. Further, the model overestimated the transverse stiffness component $C_{\mathrm{zz}}$ by about $24.6 \%$, with a standard deviation of $35.2 \%$.

260 Model parameter studies on the effect of strand orientation

261 The experimentally validated model was extended to the experimental investigations of the 262 mechanical behaviour of eco-OSB to non-tested configurations. Particular emphasis is placed on 263 examining the effect of strand orientation distribution on the elastic properties of the final panels. 264 The strand orientation of industrially produced boards is expected to be not as strictly oriented as 265 currently observed in the hand-made panels. Taking this into consideration, the model allows 
estimating elastic properties of panels from a commercial production line. The parameter study is

267 performed for pine wood as raw material, lignin adhesive, and a mean board density of $650 \mathrm{~kg} \mathrm{~m}^{-3}$. 268 Adhesive content, density profile, and the ratio of strand mass in the face and core layers 269 respectively, are the same as in the actually produced boards considered in the model validation.

The distribution of strand orientation is described by a normal distribution with a mean orientation of $0^{\circ}$ (coinciding with the $x$-axis) and a variable standard deviation. Increasing the standard deviation finally leads to a random strand orientation distribution. Figure 6 shows the pronounced effect of less tight strand orientation, modelled by increasing the standard deviation of the assumed normal distribution, on the mechanical properties of the panel. The MOE in the principal direction of the panel decreases dramatically when the strands are less aligned with the principal panel direction, whereas the MOE perpendicular to this direction increases only slightly. The in-plane shear modulus $G_{x y}$ rises with increasing standard deviation of the strand orientation distribution from about $1.4 \mathrm{GPa}$ to about $2.5 \mathrm{GPa}$. This means that higher deviations of strand orientations from the main panel direction in commercial production, improves the performance of the panel for shear stiffening applications, but degrades it for bending applications with a single pronounced load bearing direction.

\section{Conclusion}

284 Characterization of wood species as raw materials for OSB production with various methods (static vs. dynamic and compression vs. bending) led to very similar and satisfactory results. This good agreement is due to the low viscosity of dry wood and the relatively high homogeneity of the sample in the scales of L-direction and cross section (i.e., relatively small annual ring width 288 compared to the cross section characteristic length). Additionally, a micromechanics model was applied delivering all stiffness components of the input wood and, thus, completing the characterization. The mechanical behaviour of the laboratory-made panels was also determined by dynamic and static measurement techniques. The best quality (with highest stiffness) has been 
292 obtained for the panels glued with lignin-based resin. As this type of panels show the best durability 293 too, they might be suitable for developing eco-OSB panels at the industrial scale. Further, a multi294 scale model has been developed and applied in order to explore and to quantify the influences of the 295 microstructural characteristics on the mechanical behaviour of the boards for non-tested 296 configurations. The established model for eco-OSB is able to reflect suitably the microstructural 297 characteristics of raw material and adhesive properties, strand orientation, density profile and layer 298 assembly. It delivers reasonably accurate predictions for the mean elastic properties, e.g., both the 299 in-plane bending moduli and the in-plane shear modulus as well as the out-of-plane or transverse 300 stiffness tensor component. Employing the validated model for parameter studies gives insight into 301 the (micro)mechanical behaviour of strand boards. In an exemplary manner, the effect of strand 302 orientation distribution on bending and shear stiffness was demonstrated to be able to estimate the 303 influence of the production process on the mechanical properties of the panels. The combination of 304 the theoretical model, capable to describe the underlying mechanics, and complementary 305 experiments, affording direct insight into the mechanical performance, seems to be a fruitful and 306 efficient approach. This combination permits the further development of products.

308 Acknowledgements

309 The authors gratefully acknowledge Remy Marchal and Jean Claude Buteaud (from the Labomap 310 laboratory, Ecole Nationale Supérieure d'Arts et Métiers, Cluny, France) for the peeling of the 311 strands. 


\section{References}

Amusant, N., Arnould, O., Pizzi, A., Depres, A., Mansouris, R.H., Bardet, S., Baudassé, C. (2009) Biological properties of an OSB eco-product manufactured from a mixture of durable and non durable species and natural resins. Eur. J. Wood Prod. 67:439-447

Ballerini, A., Despres, A., Pizzi, A. (2005) Non-toxic, zero-emission tannin-glyoxal adhesives for wood panels. Holz Roh Werkst. 63(6):477-478

Behr, E.A. (1972) Decay and termite resistance of medium density fiberboards made from wood residue. For. Prod J. 22(12):48-51

Bordonné, P.A. (1989) Module dynamique et frottement intérieur dans le bois, mesures sur poutres flottantes en vibrations naturelles. Ph.D. thesis, Institut National Polytechnique de Lorraine.

Brancheriau L. (2006) Influence of cross section dimensions on Timoshenko's shear factor Application to wooden beams in free-free flexural vibration. Ann. For. Sci. 63:319-321

Brancheriau, L., Bailleres, H. (2002) Natural vibration analysis of clear wooden beams: a theoretical review. Wood Sci. Technol. 36:347-365

Bucur, V. Acoustics of wood. 2nd revised edition, Springer-Verlag, Berlin, 2005.

Christensen, R.M., Lo, K.H. (1979) Solutions for effective shear properties in three phase sphere and cylinder models. J. Mech. Phys. Solids 27:315-330

ECOSB Layman's report (2008) New and environmentally friendly OSB panels. LIFE Project LIFE05 ENV/L/000047

European strandard (2005) EN 789. Timber structures - Test methods - Determination of mechanical properties of wood based panels

Evans, P.D., Dimitriade, S., Cunningham, R.B., Donnelly, C.F. (2000) Medium density fibreboard manufactured from blends of white cypress pine and non-durable wood species shows increased resistance to attack by subterranean C. lacteus. Holzforschung 54(6):585-590

Faix, O. (2008) Chemie des Holzes. In: Taschenbuch der Holztechnik. Eds. Wagenführ, A., Scholz, F. Hanser Verlag, München. pp. 47-74

Garcia, R., Pizzi, A. (1998) Polycondensation and autocondensation networks in polyflavonoid tannins. II. Polycondensation versus autocondensation. J. Appl. Poly. Sci. 70:1093-1109

Garnier, S., Pizzi, A., Vorster, O., Halasz, L. (2002) Rheology of polyflavonoid tanninformaldehyde reactions before and after gelling - Part 2: Hardener influence and comparison of different tannins. J. Appl. Poly. Sci. 84(4):864-871

Goroyias, G.J., Hale, M.D. (2004) The mechanical and physical properties of strand boards treated with preservatives at different stages of manufacture. Wood Sci. Technol. 38:93-107

Guitard, D. Mécanique du matériau bois et composites. Cépaduès, Toulouse, France, 1987

Hashin, Z. (1979) Analysis of properties of fiber composites with anisotropic constituents. J. Appl. Mech. 46:543-550

Hashin, Z., Rosen, B.W. (1964) The elastic moduli of fiber-reinforced materials. J. Appl. Mech $31: 223-232$

Hofstetter, K., Hellmich, Ch., Eberhardsteiner, J. (2005) Development and experimental verification of a continuum micromechanics model for wood. Eur. J. Mech. A/Solids 24:1030-1053

Hofstetter, K., Hellmich, Ch., Eberhardsteiner, J. (2006) The influence of the microfibril angle of wood stiffness: a continuum micromechanics approach. Comput. Assist. Mech. Eng. Sci. 13:523536 
Hofstetter, K., Hellmich, Ch., Eberhardsteiner, J. (2007) Micromechanical modeling of solid-type and plate-type deformation patterns within softwood materials. A review and an improved approach. Holzforschung 61(4):343-351

Kartal, S.N., Green III, F. (2003) Decay and termite resistance of medium density fibreboard (MDF) made from different wood species. Inter. Biodeter. Biodegr. 51:29-35

Kirkpatrick, J.W., Barnes, H.M. (2006) Biocide treatments for wood composites - A review. In: 37th annual meeting of the International Research Group on Wood Preservation. IRG/WP 0640323. $21 \mathrm{p}$

Lei, H., Pizzi, A., Du, G. (2007) Environment-friendly, mixed tannin/lignin wood resins. J. Appl. Poly. Sci. 107(1):203-209

Mansouri, N.E., Pizzi, A., Salvado, J. (2007a) Lignin-based wood panel adhesives without formaldehyde. Holz Roh Werkst. 65(1):65-70

Mansouri, N.E., Pizzi, A., Salvado, J. (2007b) Lignin-based polycondensation resins for wood adhesives. J. Appl. Pol. Sci. 103:1690-1699

Muin, M., Tsunoda, K. (2003) Termicidal performance of wood based composites treated with silafluofen using supercritical carbon dioxide. Holzforschung 57(6):585-592

Osman, Z., Pizzi, A. (2002) Comparison of gelling reaction effectiveness of procyanidin tannins for wood adhesives. Hols Roh Werkst. 60:328

Petterson, R.C. (1984) The chemical composition of wood. In: The chemistry of solid wood. Eds. Rowell, R. American Chemical Society, Washington D.C. pp. 57-126

Stürzenbecher, R., Hofstetter, K., Bogensperger, Th., Schickhofer, G., Eberhardsteiner, J. (2010a) Development of high-performance strand boards: engineering design and experimental investigations. Wood Sci. Technol. 44(1):13-29

Stürzenbecher, R., Hofstetter, K., Schickhofer, G., Eberhardsteiner, J. (2010b) Development of high-performance strand boards: multiscale modeling of anisotropic elasticity. Wood Sci. Technol. 44(2):205-223

Wan, H., Wang, X.M., Yang, D.Q. (2007) Utilizing eastern white Cedar to improve the resistance of strand boards to mold and decay fungi. For. Prod. J. 57(3):54-59

Yalinkilic, M.K., Immamura, Y., Takahashi, M., Kakaycioglu, H., Dermici, G.N., Ozdemir, T. (1998) Biological, physical and mechanical properties of particleboards manufactured from waste leaves. Inter. Biodeter. Biodegr. 41:75-84 
Table 1. Parameters of panel manufacturing

\begin{tabular}{ll}
\hline Panel dimensions & $350 \times 350 \times 14 \mathrm{~mm}^{3}$ \\
Three layers panel construction & Core perpendicular to face flakes \\
Mass distribution (side/core/side) & $20 \% / 60 \% / 20 \%$ \\
Wood species & Pine, cypress \\
Target mat moisture content & $6-7 \%$ \\
Resin mass content & $13 \%$ side and $11 \%$ core \\
Blender type for mixing strands with resin & Dakota \\
Blender rotation speed & $900 \mathrm{rpm}$ \\
Pressing cycle for gluing & $90 \mathrm{~s} 35$ bar, $120 \mathrm{~s} 16$ bar, $150 \mathrm{~s} 8 \mathrm{bar}$ \\
Press temperature & $175^{\circ} \mathrm{C}$ (plate surface) \\
Total press time & $6 \mathrm{~min}$ \\
Replicate & 3 \\
\hline
\end{tabular}


1 Table 2. Mean values of measured wood bulk properties obtained by different measurement methods and by micromechanical model predictions for

2 the nine independent elastic constants of bulk wood.

\begin{tabular}{|c|c|c|c|c|c|}
\hline Wood & Properties & $\begin{array}{l}\text { Beam free vibration }(\sim 700 \mathrm{~Hz}) \\
\text { Sample: } 20 \times 20 \times 360 \mathrm{~mm}^{3}\end{array}$ & $\begin{array}{l}\text { Ultrasound } \\
(1 \mathrm{MHz})\end{array}$ & $\begin{array}{l}\text { Static compression test } \\
\text { Sample: } 40 \times 40 \times 40 \mathrm{~mm}^{3}\end{array}$ & Computed \\
\hline \multirow{10}{*}{$\begin{array}{l}\text { Cypress } \\
\text { (Cupressus } \\
\text { sempervirens) }\end{array}$} & $\rho\left(\mathrm{kg} \mathrm{m}^{-3}\right)$ & $579 \pm 4$ & $569 \pm 8$ & 580 & \\
\hline & $E_{\mathrm{R}}(\mathrm{GPa})$ & & $1.99 \pm 0.09$ & $1.75 \pm 0.03$ & 1.21 \\
\hline & $E_{\mathrm{T}}(\mathrm{GPa})$ & & $1.44 \pm 0.08$ & $1.16 \pm 0.04$ & 0.86 \\
\hline & $E_{\mathrm{L}}(\mathrm{GPa})$ & $13.17 \pm 0.97$ & $12.55 \pm 0.96$ & $11.21 \pm 1.79$ & 13.03 \\
\hline & $v_{\mathrm{RT}}$ & & & $0.63 \pm 0.05$ & 0.49 \\
\hline & $v_{\mathrm{LR}}$ & & & $0.36 \pm 0.03$ & 0.32 \\
\hline & $v_{\mathrm{LT}}$ & & & $0.71 \pm 0.22$ & 0.37 \\
\hline & $G_{T L}(G P a)$ & $1.00 \pm 0.01$ & & & 1.00 \\
\hline & $G_{L R}(G P a)$ & $1.12 \pm 0.06$ & & & 1.02 \\
\hline & $G_{R T}(\mathrm{GPa})$ & & & & 0.12 \\
\hline \multirow{10}{*}{$\begin{array}{l}\text { Pine } \\
\text { (Pinus sylvestris) }\end{array}$} & $\rho\left(\mathrm{kg} \mathrm{m}^{-3}\right)$ & $547 \pm 26$ & $537 \pm 21$ & 535 & 550 \\
\hline & $E_{\mathrm{R}}(\mathrm{GPa})$ & & $1.86 \pm 0.12$ & $1.79 \pm 0.01$ & 1.13 \\
\hline & $E_{\mathrm{T}}(\mathrm{GPa})$ & & $0.73 \pm 0.19$ & $0.91 \pm 0.01$ & 0.80 \\
\hline & $E_{\mathrm{L}}(\mathrm{GPa})$ & $14.39 \pm 1.73$ & $13.99 \pm 1.12$ & $15.85 \pm 0.25$ & 13.84 \\
\hline & $v_{\mathrm{RT}}$ & & & $0.58 \pm 0.14$ & 0.52 \\
\hline & $v_{\mathrm{LR}}$ & & & -- & 0.32 \\
\hline & $v_{L T}$ & & & $0.61 \pm 0.29$ & 0.36 \\
\hline & $G_{T L}(G P a)$ & $1.02 \pm 0.09$ & & & 0.98 \\
\hline & $G_{L R}(G P a)$ & $1.37 \pm 0.10$ & & & 1.00 \\
\hline & $G_{R T}(\mathrm{GPa})$ & & & & 0.10 \\
\hline
\end{tabular}


5 Table 3. Elastic properties of the manufactured panels: median values and range (in parenthesis). Density values for the edgeways free vibration

6 bending are the same as the face down bending in the same direction.

\begin{tabular}{|c|c|c|c|c|c|c|c|c|c|c|c|}
\hline \multirow{3}{*}{$\begin{array}{c}\text { Resin } \\
\text { base }\end{array}$} & \multirow{3}{*}{$\begin{array}{l}\text { Cypress } \\
\text { content } \\
\text { (\% wt.) }\end{array}$} & \multicolumn{3}{|c|}{$\begin{array}{c}E_{X}(\mathrm{GPa}) \\
\text { Face down bending }\end{array}$} & \multicolumn{3}{|c|}{$\begin{array}{c}E_{\mathrm{Y}}(\mathrm{GPa}) \\
\text { Face down bending }\end{array}$} & \multirow{2}{*}{\multicolumn{2}{|c|}{$\begin{array}{c}G_{X Y}(\mathrm{GPa}) \\
\text { Edgeways free vibration } \\
\text { Bending }(\sim 1.5 \mathrm{kHz})\end{array}$}} & \multicolumn{2}{|c|}{$C_{\mathrm{ZZ}}(\mathrm{GPa})$} \\
\hline & & \multirow{2}{*}{$\begin{array}{l}\text { Density } \\
\left(\mathrm{kg} \mathrm{m}^{-3}\right)\end{array}$} & \multirow[b]{2}{*}{ Static } & \multirow{2}{*}{$\begin{array}{l}\text { Free vibration } \\
(\sim 500 \mathrm{~Hz})\end{array}$} & \multirow{2}{*}{$\begin{array}{l}\text { Density } \\
\left(\mathrm{kg} \mathrm{m}^{-3}\right)\end{array}$} & \multirow[b]{2}{*}{ static } & \multirow{2}{*}{$\begin{array}{c}\text { Free vibration } \\
(\sim 500 \mathrm{~Hz})\end{array}$} & & & \multirow{2}{*}{$\begin{array}{l}\text { Density } \\
\left(\mathrm{kg} \mathrm{m}^{-3}\right)\end{array}$} & \multirow{2}{*}{$\begin{array}{c}\text { Ultrasound } \\
(100 \mathrm{kHz})\end{array}$} \\
\hline & & & & & & & & $x$ sample & y sample & & \\
\hline \multirow{4}{*}{ Tannin } & 100 & $668(35)$ & $10.9(0.3)$ & $9.6(2.7)$ & $643(23)$ & $4(0.1)$ & $4.1(0.6)$ & $1.35(0.4)$ & $1.8(1.9)$ & $649(40)$ & $0.65(0.25)$ \\
\hline & 75 & $658(10)$ & $8(2.2)$ & $7.7(1)$ & $667(32)$ & $4.9(4)$ & 5) & 1.3 & $0.9(0.2)$ & 705 (26) & 0.6 \\
\hline & 50 & $664(15)$ & $13.5(1.4)$ & $11.9(3.1)$ & $657(15)$ & $5.1(1)$ & $4.7(1.8)$ & $1.1(0.7)$ & $1(0.5)$ & $661(61)$ & $0.55(0.18)$ \\
\hline & 0 & $650(28)$ & $5.4(2.3)$ & $7.8(1.6)$ & $667(53)$ & $3(0.3)$ & $3.3(0.5)$ & $0.7(1.2)$ & $2.1(4.4)$ & $690(58)$ & $0.36(0.08)$ \\
\hline \multirow{4}{*}{ Lignin } & 100 & $636(27)$ & $10(1.9)$ & $9.5(0.6)$ & $661(68)$ & $4.5(1.5)$ & $4.4(1.2)$ & $1.5(1)$ & $1.3(1.4)$ & 654 (153) & $0.85(0.38)$ \\
\hline & 75 & $673(90)$ & $12.9(2.4)$ & $11.2(2.7)$ & $628(41)$ & $4.9(0.2)$ & $4.9(0.7)$ & $1.6(1)$ & $1.3(0.7)$ & $636(150)$ & $0.67(0.25)$ \\
\hline & 50 & $675(37)$ & $10.7(2.3)$ & $11.1(0.8)$ & $643(46)$ & $4.4(4.4)$ & $4(0.7)$ & $1.4(0.4)$ & $2.1(1)$ & $647(174)$ & $0.57(0.39)$ \\
\hline & 0 & $664(80)$ & $12.1(1)$ & $11.3(0.9)$ & $652(29)$ & $3.4(4)$ & $5.9(2.2)$ & $1.1(0.8)$ & $1.1(0.4)$ & 643 (142) & $0.52(0.28)$ \\
\hline
\end{tabular}




\section{Figures' legend}

8

9 Figure 1. Cutting plan for specimens for measurements on the raw material.

10 Figure 2. Face view of a manufactured OSB (50\% cypress-50\% pine with the lignin based resin)

11 and cutting plan

12 Figure 3. Characteristic measured density profile, DP, in thickness and layer-wise average for 13 modelling purpose.

14 Figure 4. Strand orientations measured on the surfaces of three produced panels and normal 15 distribution adjustment to the data $\left(\mu=0.4^{\circ}, \sigma=4.9^{\circ}\right)$.

16 Figure 5. Comparison of experimental values from bending free vibration tests and corresponding 17 model predictions.

18 Figure 6. Effect of strand orientation on the elastic bending constants. 


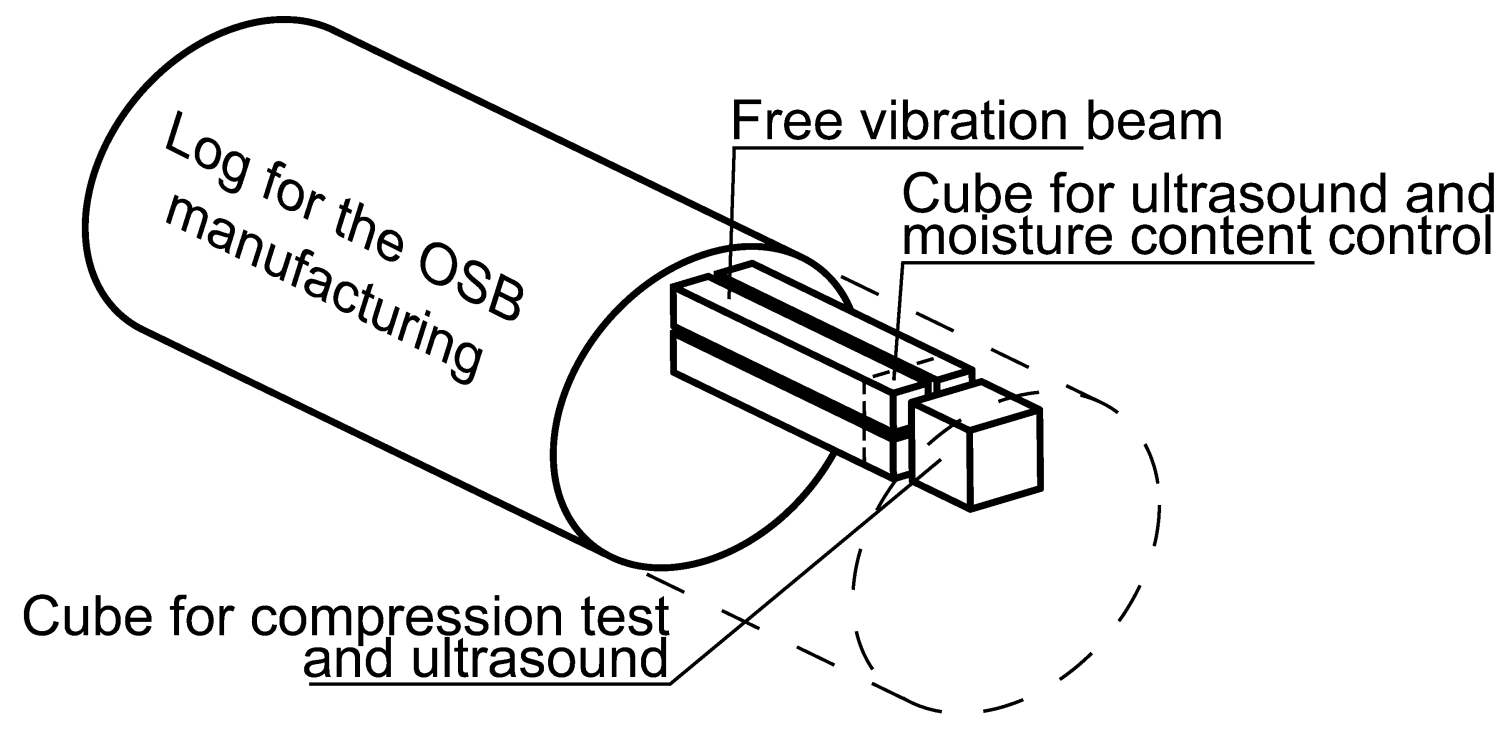

21 Figure 1. Cutting plan for specimens for measurements on the raw material. 


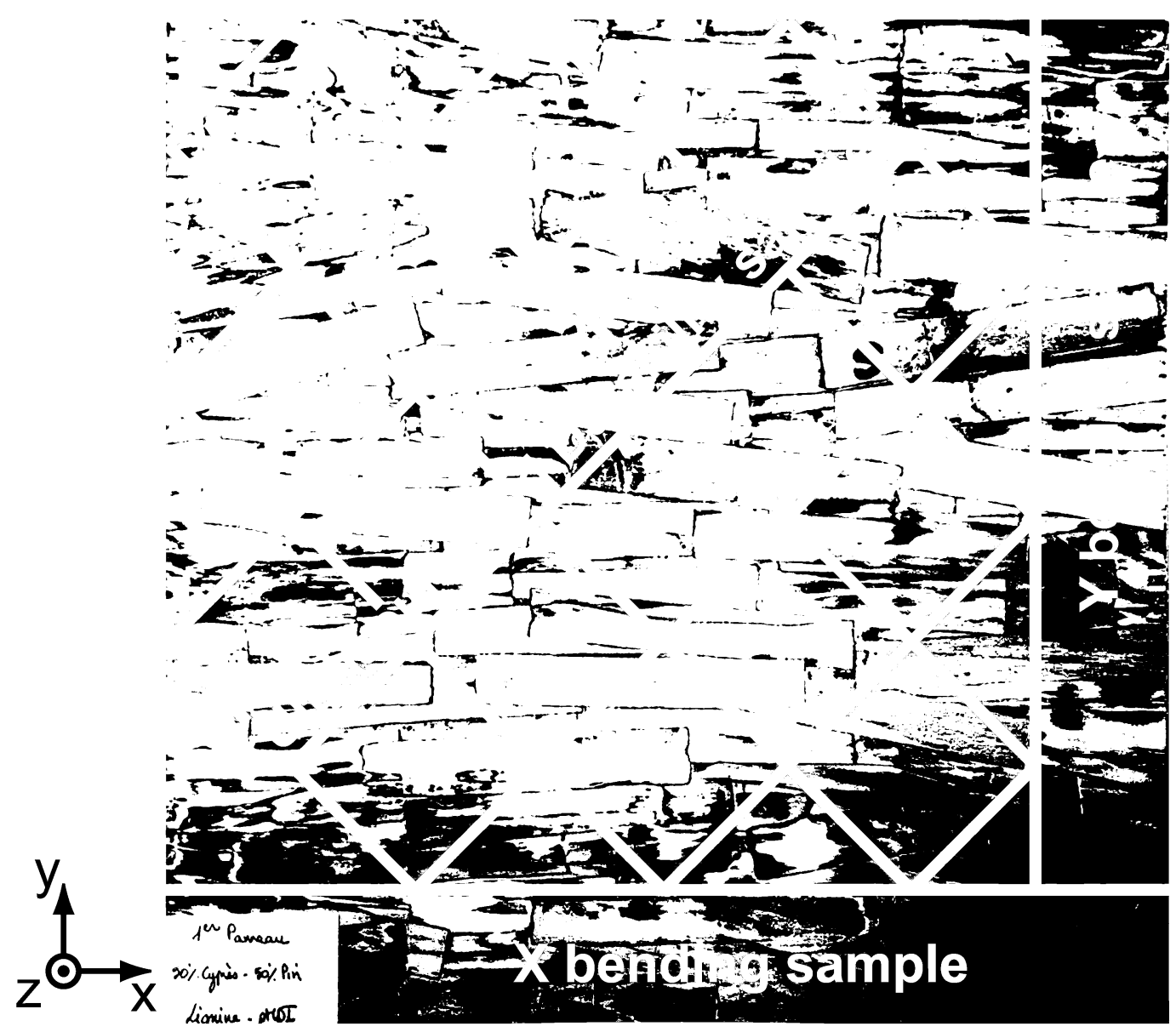

24 Figure 2. Face view of a manufactured OSB (50\% cypress-50\% pine with the lignin based resin) 25 and cutting plan. 


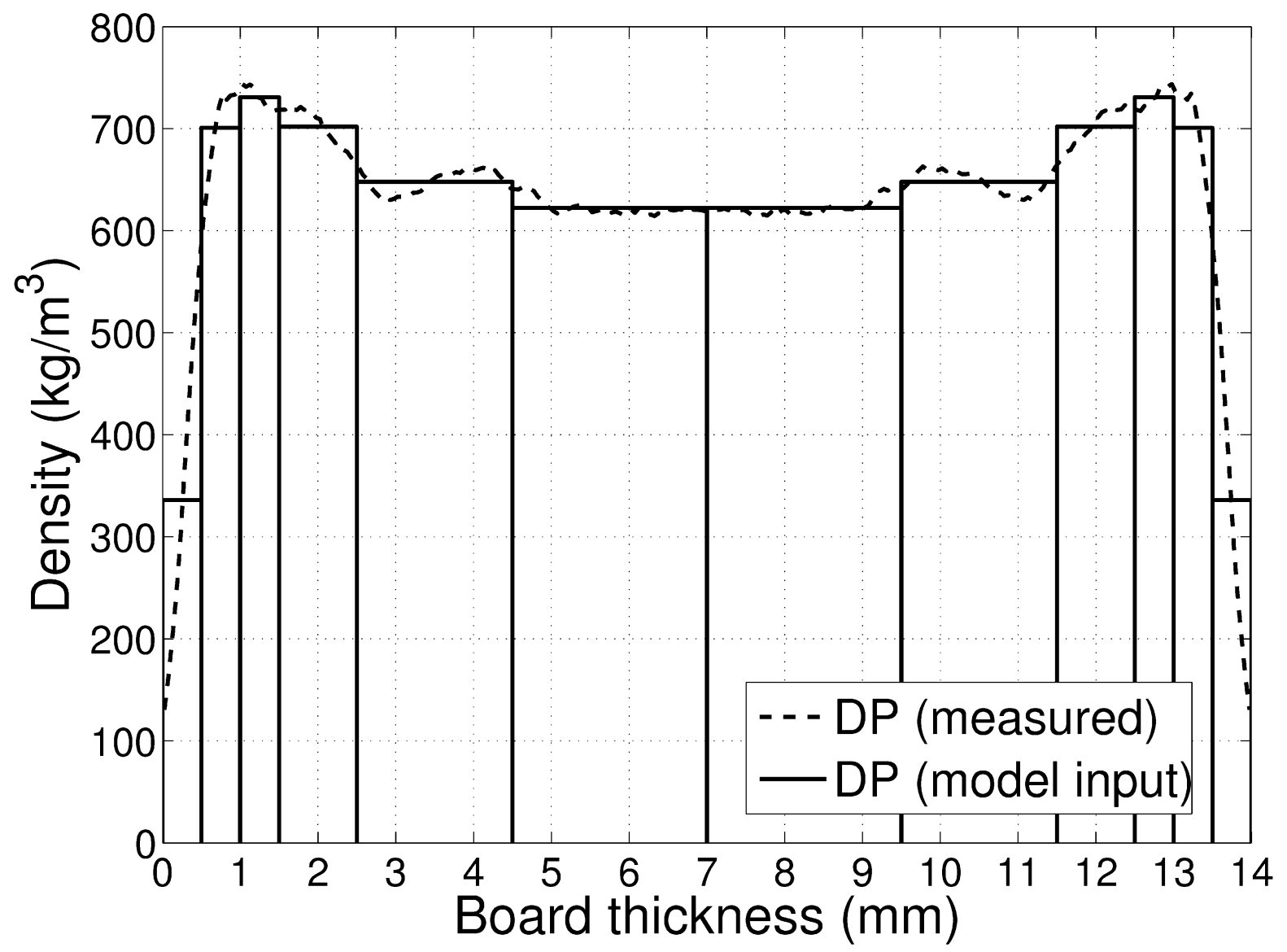

27

28 Figure 3. Characteristic measured density profile, DP, in thickness and layer-wise average for 29 modelling purpose. 


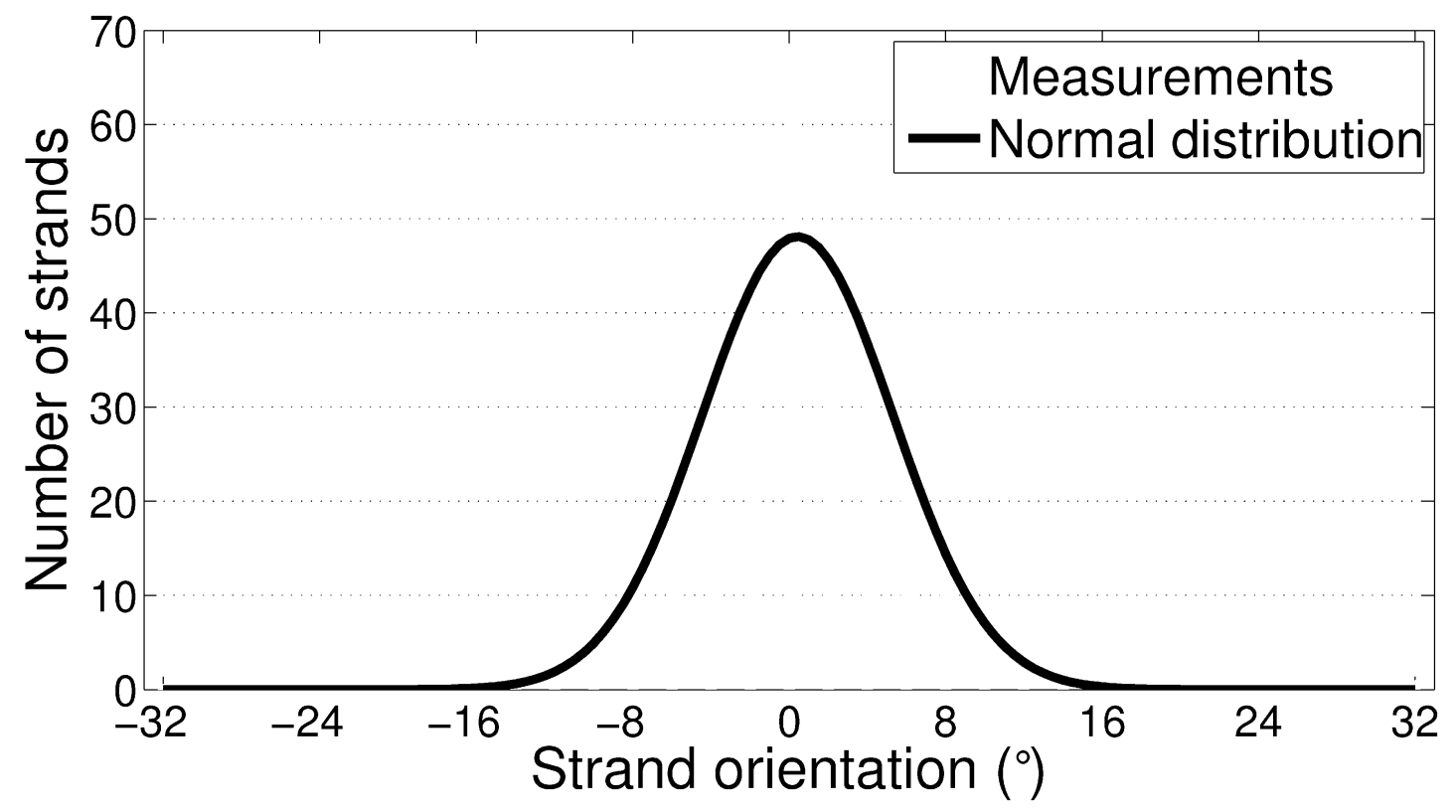

32 Figure 4. Strand orientations measured on the surfaces of three produced panels and normal

33 distribution adjustment to the data $\left(\mu=0.4^{\circ}, \sigma=4.9^{\circ}\right)$. 


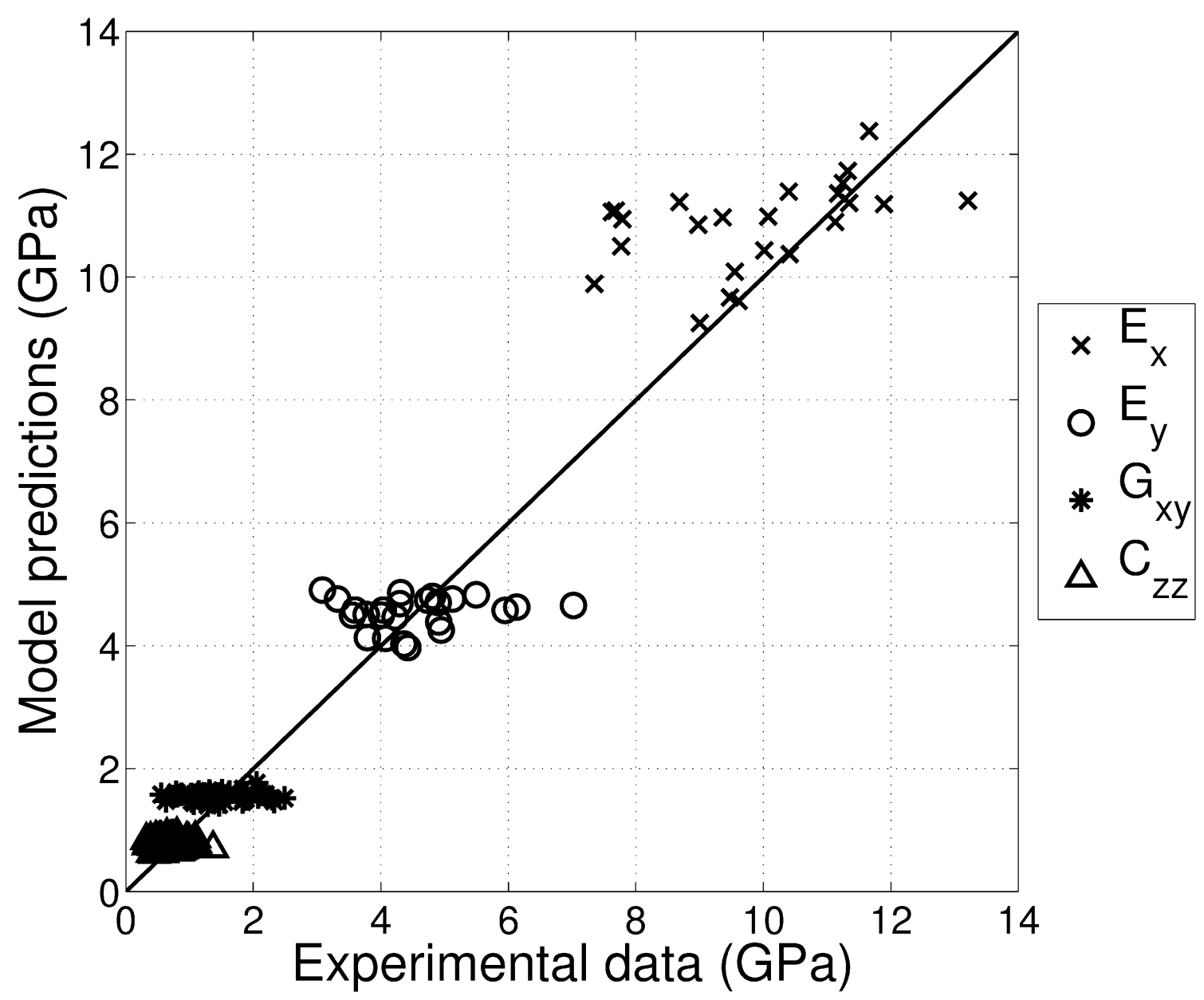

35

36 Figure 5. Comparison of experimental values from bending free vibration tests and corresponding 37 model predictions. 


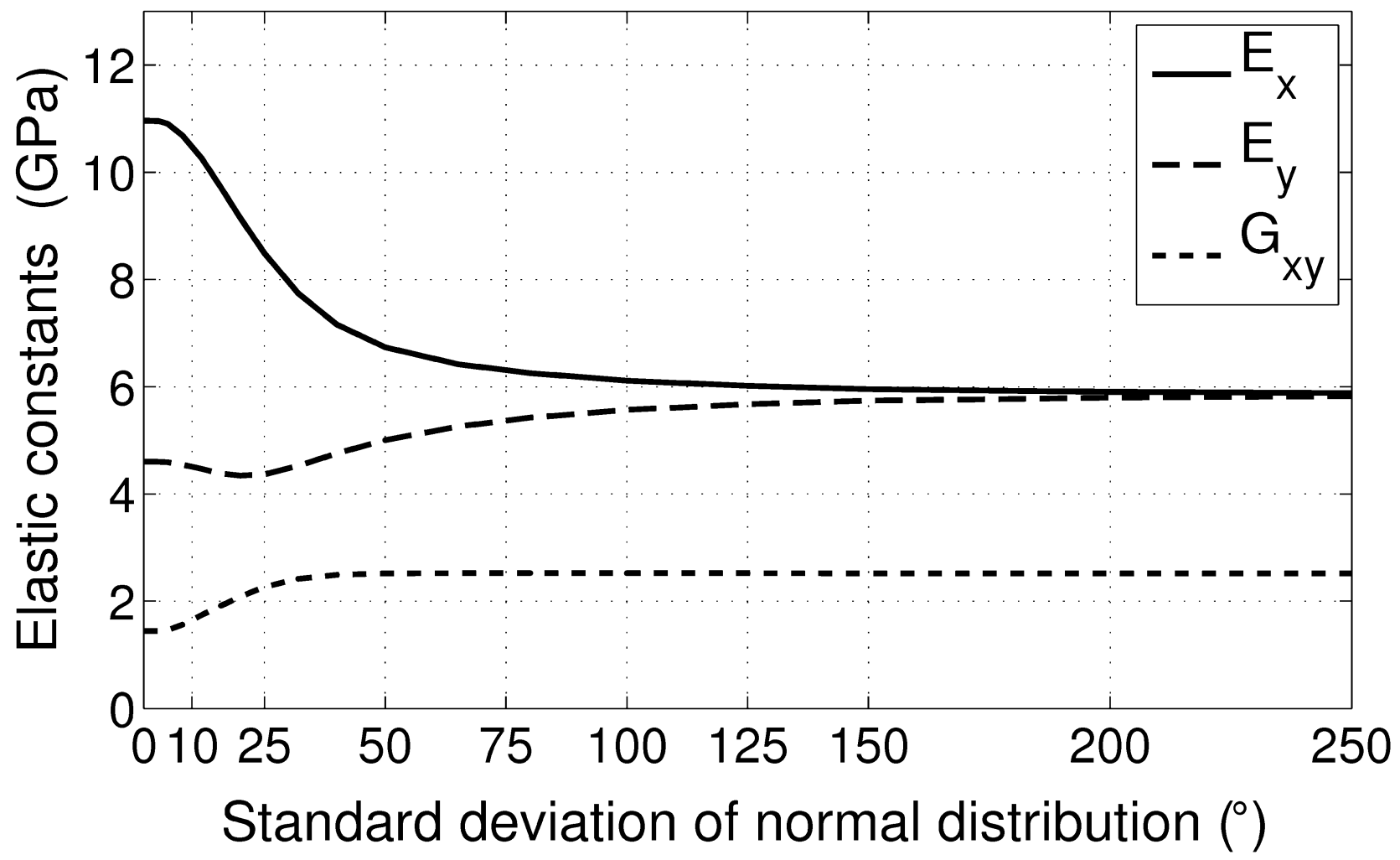

40 Figure 6. Effect of strand orientation on the elastic bending constants. 